\title{
Historical perspectives of The American Association for Thoracic Surgery: W. Gerald Austen
}

\author{
Cameron D. Wright, MD
}

William Gerald Austen, "Jerry" or "WGA," the 69th president of The American Association for Thoracic Surgery (AATS), was born on January 20, 1930, in Akron, Ohio. When he graduated from high school at the age of 17 years, Austen moved to Boston, which he has since called home. Dr Austen received his Bachelor of Science in mechanical engineering from Massachusetts Institute of Technology and Doctor of Medicine from Harvard Medical School. He started his internship at Massachusetts General Hospital (MGH) in July 1955. Shortly thereafter, using his background in engineering, Dr Austen worked with MGH faculty Robert Shaw to develop the first cardiopulmonary bypass (CPB) machine at $\mathrm{MGH}$. The standard resident schedule at that time was 36 hours on, 12 hours off. Dr Austen, noting specifically that he was single at the time regaled, "On my night off, I actually spent about 4 or 5 hours doing research in either the basement of the MGH or Bob Shaw's house. It was wonderful." Austen and Shaw initially tested the CPB machine on dogs with J. Gordon Scannell, 58th AATS president, as cardiac surgeon. Austen admits, "We never had a dog that lived," but the CPB machine, which initially cost approximately $\$ 400$ to build, seemed to function well. The first 10 patients they tested in 1956 all had been chosen because it was determined by the medical staff that they had end-stage disease with "less than 30 days to live." With Austen and Shaw behind the pump, 5 of their first 10 patients who were at the end of life lived and made a full recovery. It was the beginning of cardiac surgery at MGH. "When I look at it now, compared to what everyone is doing in science today, I guess I would say that it was pretty rudimentary. But it needed to be done because none of these things were known. It was just the right thing for an engineer to be involved in." Austen published 15 peer-reviewed articles by the end of his residency, a formidable task for someone on call every other night.

Dr Austen did additional training in general surgery at King College Hospital in London and cardiothoracic surgery at the General Infirmary in Leeds, which was a busy

\footnotetext{
From the Massachusetts General Hospital, Boston, Mass.

Disclosures: Authors have nothing to disclose with regard to commercial support.

Received for publication Feb 24, 2012; accepted for publication April 6, 2012; available ahead of print May 24, 2012.

Address for reprints: Cameron D. Wright, MD, Massachusetts General Hospital, Thoracic Surgery, Blake 1570, 55 Fruit St, Boston, MA 02114 (E-mail: wright. cameron@mgh.harvard.edu).

J Thorac Cardiovasc Surg 2013;146:745-7

$0022-5223 / \$ 36.00$

Copyright (C) 2013 by The American Association for Thoracic Surgery doi:10.1016/j.jtcvs.2012.04.015
}

unit at the time. In 1960, he was appointed "Super Chief Resident" of the East Surgical Service after only 41/2 years of training, far ahead of the norm. After his final clinical year at MGH, Dr Edward Churchill, 28th AATS president and Austen's Chairman, arranged 2 years of clinical and research work for him in cardiac surgery at the National Institutes of Health under Glenn Morrow's leadership. Austen's partners at the National Institutes of Health were Paul Ebert, 68th AATS president, and Lazar Greenfield, eventual chief of surgery at the University of Michigan for many years.

In 1963, Austen returned to Boston to join the faculty, with his mandate being to advance and lead cardiac surgery at MGH (Figure 1). Dr Austen was a pioneer in the surgical treatment of the complications of myocardial infarction and in the development of systems to support the failing heart. He reported the first successful mitral valve replacement for an acutely ruptured papillary muscle after myocardial infarction in 1968. ${ }^{1}$ Dr Austen's promotion through the ranks of Harvard Medical School was rapid and unprecedented, as was his abbreviated residency. After his initial appointment as Instructor in Surgery in 1963, Austen quickly progressed to Associate Professor in 1965 and Professor of Surgery in 1966! He was honored with the Edward D. Churchill Chair in Surgery in 1974. Dr Austen was appointed Chief of the Surgical Services at MGH in 1969 at the age of 39 years and held that position for approximately 29 years. At that time, the Department of Surgery was relatively undifferentiated in terms of specialty divisions. Dr Austen thought that specialization was essential to become a leading academic department, so he created 10 divisions within the department and appointed a chief for each division, an organizational model that continues today. In addition, most of the MGH faculty were not full-time academics but in private practice. Dr Austen thought it was essential to create a group practice in which every member worked together toward a common mission, to create the best academic department of surgery in the country. It took several years, but he was finally able to coax all the established members of the department to adopt his vision. Having a singular academic group practice allowed Dr Austen to the use the excess funds generated from well-reimbursed specialties to support some of the poorly reimbursed specialties that, in turn, allowed him to recruit and retain the best surgeons possible across the entire department. Many of the residents, fellows, and staff who served under Dr Austen have gone on to important leadership roles; more than 20 have become Chairman of Surgery in the United States and abroad, and more than 150 have become Division Chiefs. During his 


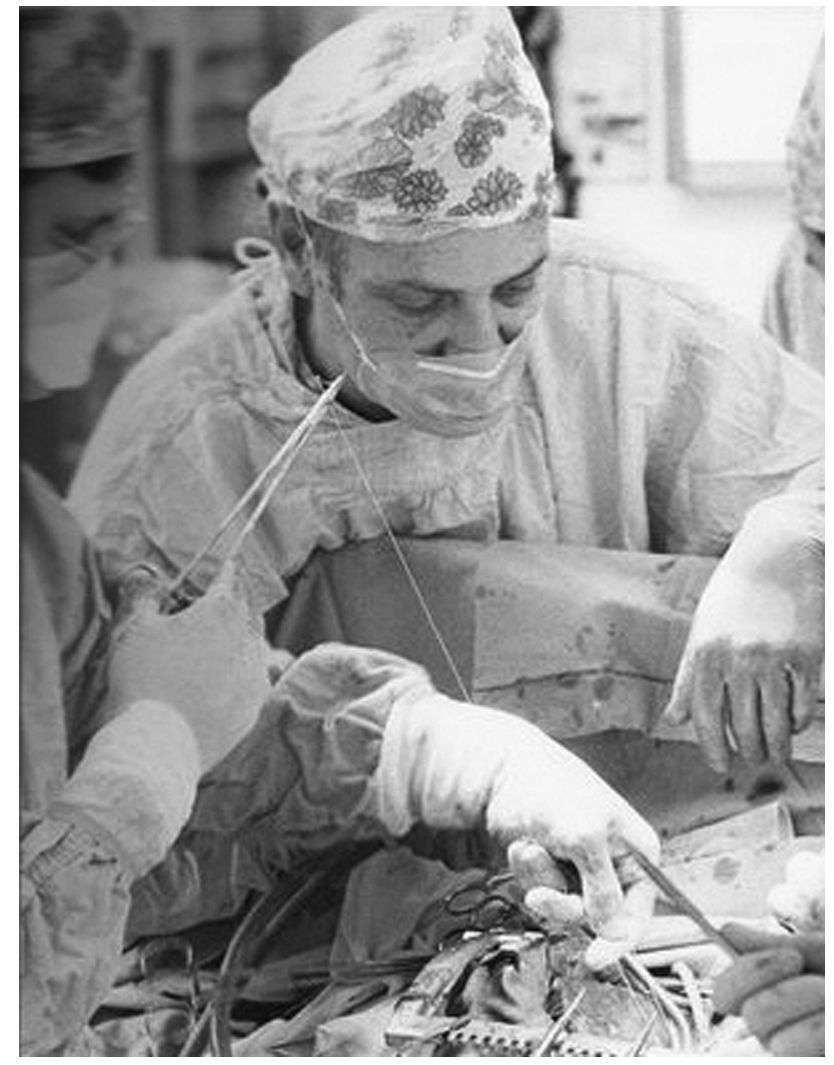

FIGURE 1. Dr Austen operating in 1982. He was assisting one of his residents from the head of the operating table so he could keep a proper eye on his trainee.

tenure, he also raised the funds for 10 endowed Harvard Chairs, the most generated by one individual leader in the medical school's history. When he stepped down as Chief of Surgery, the W. Gerald Austen Chair of Surgery was established at Harvard Medical School and MGH.

In addition to being President of the AATS (1988-1989), Dr Austen was also President of the Association for Academic Surgery, Society of University Surgeons, American Surgical Association, American Heart Association, and American College of Surgeons! His AATS Presidential Address was entitled "Eight Former Presidents of the AATS. The Boston Connection" and summarized the careers of the 8 prior AATS presidents who hailed from Boston, starting with Samuel Robinson and ending with Dr Scannell. ${ }^{2}$ Dr Austen served on the editorial boards of 12 medical journals, was visiting professor at 59 medical schools and clinics, and was awarded 4 honorary doctorates. Dr Austen attributes his astounding success to "luck and hard work." From a personal perspective, his leadership and interpersonal skills were without peer and made him a beloved chief at MGH. Dr Austen had just the right touch in dealing with his sometimes challenging faculty. He was a master persuader who excelled at achieving fair consensus on contentious matters within the department, often with the
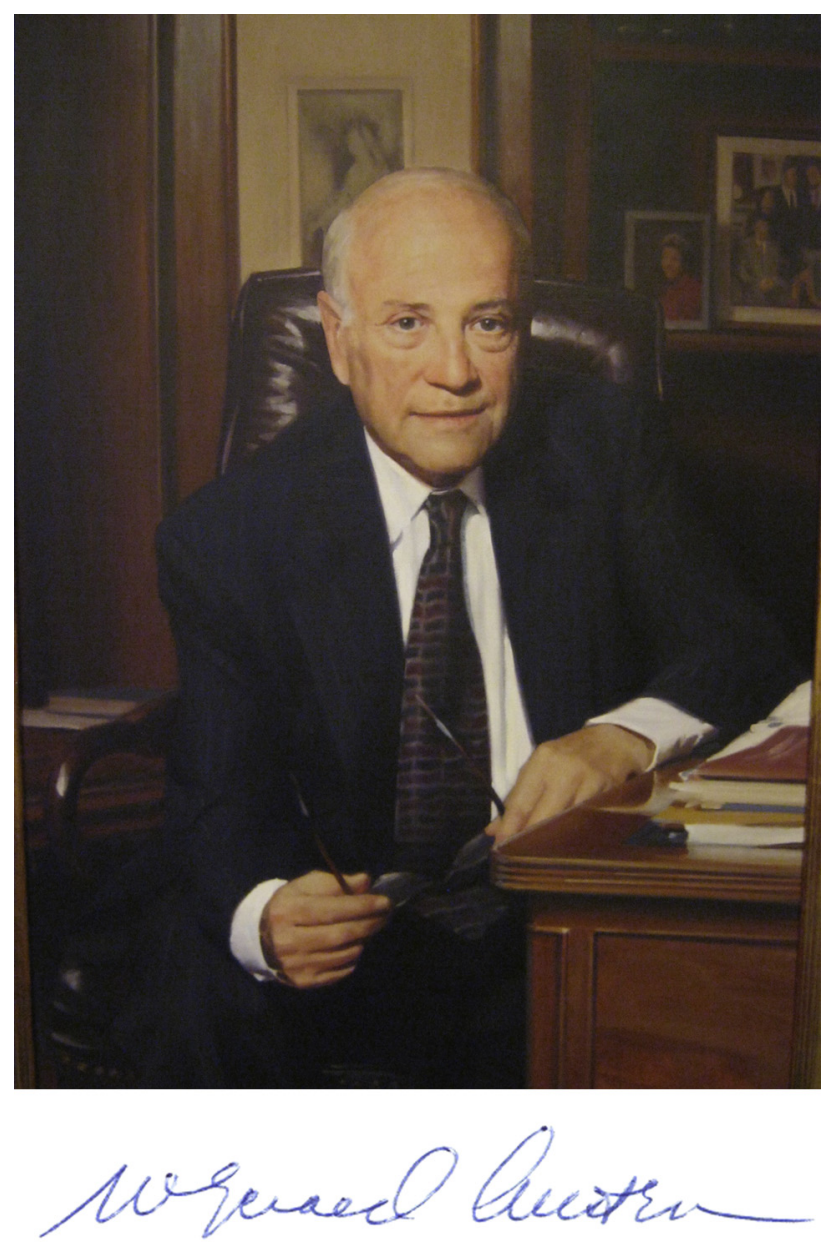

\section{W. Gerald Austen, M.D.}

FIGURE 2. Top, Formal MGH portrait of Dr Austen painted during his last year as Surgeon-in-Chief of MGH (1997). He is portrayed at his desk in his office on White 5 in his characteristic pose while talking with a colleague in a nearby chair. Bottom, Dr Austen's signature.

faculty feeling rather "warm and fuzzy" about the experience and without them necessarily understanding in retrospect how it all had transpired (Figure 2).

Edward Churchill was Dr Austen's ultimate mentor and facilitated many aspects of his training and career. Dr Austen admired Churchill's culture of respect for "residents as colleagues" and "faculty as partners" and strived to maintain a similar degree of fruitful support for resident education and his faculty throughout his tenure as chief. Dr Austen is the acknowledged "godfather" of MGH. He was the founding president and chief executive officer of the Massachusetts General Physicians Organization and was a founding Trustee of Partners Healthcare System. Since 1980, he has co-chaired the MGH Philanthropy Program and has raised more than 2 billion dollars.

Jerry married his wife, Patty, in 1961 and has 4 children, 2 of whom are physicians at his beloved MGH (Jay, Chief of 
Plastic Surgery, and Elizabeth in neuroendocrinology). He also has 10 grandchildren. Patty has served admirably as the "mother" of the Department of Surgery and has opened her home to host innumerable wonderful holiday and summer parties over the years. It seemed remarkable to visitors that she "knew everybody's name, as if she had known them for years." She had a "people's touch," as did Jerry. Jerry works full-time at MGH and can be found in his office hard at work every day, accessible as always with an everpresent smile on his face. Dr Austen continues as the Edward D. Churchill Distinguished Professor of Surgery at Harvard Medical School and serves on many national boards, including Massachusetts Institute of Technology, as a Life Member of the Corporation, Emeritus, and the Knight Foundation, a philanthropic research organization based in his hometown of Akron, as Chairman, Emeritus.

When asked recently of his vision of cardiothoracic training in these difficult times, Dr Austen acknowledged the challenges of the long duration of training, the demanding lifestyle in a time that values the opposite, and the declining reimbursements for increased work. Although he believes the current work-hour restrictions are too rigid, he recognizes the value of a better balance between work and family. $\mathrm{He}$ also believes the current educational programs available to residents are far superior to the old approach of simply "living in the hospital without any formal teaching." Dr Austen believes that the recent darker hours of concern about the lack of interest of young trainees in cardiothoracic surgery training are receding and that we have a bright future ahead of us.

\section{References}

1. Austen WG, Sokol DM, DeSanctis RW, Sanders CA. Surgical management of papillary muscle rupture complicating myocardial infraction. $N$ Engl J Med. 1968;278:1137-41.

2. Austen WGA. Eight former presidents of the AATS. The Boston connection. $J$ Thorac Cardiovasc Surg. 1989;98:643-58. 